\title{
Comparison of Dabigatran and Uninterrupted Warfarin in Patients With Atrial Fibrillation Undergoing Cardiac Rhythm Device Implantations

\author{
- Case-Control Study -
}

Jedrzej Kosiuk, MD; Emmanuel Koutalas, MD; Michael Doering, MD; Sotirios Nedios, MD; Philipp Sommer, MD; Sascha Rolf, MD; Angeliki Darma, MD; Ole A. Breithardt, MD; Borislav Dinov, MD; Gerhard Hindricks, MD; Sergio Richter, MD; Andreas Bollmann, MD, PhD

\begin{abstract}
Background: The incidence of postoperative complications following pacemaker or implantable cardioverter-defibrillator implantations in patients treated with new oral anticoagulation agents has not been studied. Here we present a first comparison of complications after cardiac rhythm device (CRD) implantations in patients with atrial fibrillation (AF) treated with dabigatran or uninterrupted warfarin.
\end{abstract}

\begin{abstract}
Methods and Results: Using a case-control study design, we compared complications within 30 days after 236 CRD procedures performed under uninterrupted warfarin $(n=118)$ or interrupted dabigatran $(n=118)$. There were no significant differences in the baseline characteristics of both groups. In the warfarin group, $9(8 \%)$ pocket hematomas were observed vs. $3(3 \%)$ in the dabigatran group $(\mathrm{P}=0.075)$. Two complications in the warfarin group necessitated surgical intervention as opposed to none in the dabigatran group $(P=0.156)$. The postprocedural blood loss expressed as a drop in hemoglobin was significantly greater in the warfarin group $(-0.9 \pm 0.7 \mathrm{vs} .-0.5 \pm 0.4 \mathrm{mmol} / \mathrm{L}, P=0.023)$. In the dabigatran group, 1 case of transient ischemic attack occurred. The mean time to hospital discharge was shorter in patients treated with dabigatran $(2.5 \pm 2.3$ vs. $3.8 \pm 4.1$ days, $P=0.02)$.
\end{abstract}

Conclusions: The incidence and severity of bleeding complications may be lower in patients treated with periprocedurally discontinued dabigatran when compared with uninterrupted warfarin therapy. Further evaluation of periinterventional complications and establishment of an optimal anticoagulation management protocol are needed. (Circ J 2014; 78: 2402-2407)

Key Words: Bleeding; Complications; Dabigatran; Implantable cardioverter-defibrillators; Pacemakers

$\mathbf{T}$ he high prevalence of atrial fibrillation (AF) and the subsequent need for anticoagulation in patients with cardiac rhythm devices (CRD) leads to increased peri-interventional bleeding complication rates. ${ }^{1-4}$ The periprocedural management of patients receiving long-term oral anticoagulant therapy remains a common but difficult problem, with limited evidence ensuring optimal treatment. ${ }^{5} \mathrm{Re}$ cently, uninterrupted warfarin use in patients undergoing pacemaker (PM) or implantable cardioverter-defibrillator (ICD) implantations has been shown to reduce bleeding complications to $3.5 \%$ when compared with bridging with heparin. ${ }^{6}$ The novel oral anticoagulants (NOAC) with their very short time of elimination and rapid onset of action may simplify and improve patient care in the perioperative setting. However, be- cause of the lack of experience with those new drugs, the questions concerning optimal peri-interventional management remain unanswered. Moreover, only very limited data exists on the safety and efficacy of new oral anticoagulants, such as dabigatran, in patients undergoing CRD implantation ${ }^{7}$ and a comparison with uninterrupted warfarin as the potential gold-standard has not yet been conducted.

Therefore, we present for the first time results of periprocedural treatment with dabigatran in contrast to uninterrupted warfarin in terms of bleeding and thromboembolic complications, blood loss and hospitalization.

Received June 26, 2014; revised manuscript received July 11, 2014; accepted July 18, 2014; released online August 22, 2014 Time for primary review: 6 days

Department of Electrophysiology, Heart Center Leipzig, Leipzig, Germany

Mailing address: Jedrzej Kosiuk, MD, Department of Electrophysiology, Heart Center Leipzig, Strümpellstr. 39, 04289 Leipzig, Germany.

E-mail: jedrzejkosiuk@hotmail.com

ISSN-1346-9843 doi:10.1253/circj.CJ-14-0665

All rights are reserved to the Japanese Circulation Society. For permissions, please e-mail: cj@j-circ.or.jp 


\begin{tabular}{|c|c|c|c|}
\hline & $\begin{array}{c}\text { Dabigatran } \\
(n=118)\end{array}$ & $\begin{array}{c}\text { Warfarin } \\
(n=118)\end{array}$ & $P$ value \\
\hline \multicolumn{4}{|l|}{ Clinical characteristics } \\
\hline Age, (years $\pm \mathrm{SD})$ & $73 \pm 11$ & $74 \pm 10$ & 0.412 \\
\hline Male, n (\%) & $76(64)$ & $74(64)$ & 0.787 \\
\hline Diabetes mellitus, $\mathrm{n}(\%)$ & $31(26)$ & $40(34)$ & 0.201 \\
\hline Coronary artery disease, $\mathrm{n}(\%)$ & $35(30)$ & $38(32)$ & 0.673 \\
\hline Hypertension, n (\%) & $110(93)$ & $108(92)$ & 0.624 \\
\hline Median $\mathrm{CHA}_{2} \mathrm{DS}_{2}$-VASc score, (IQR) & $4(3-5)$ & $4(3-5)$ & 0.182 \\
\hline$\beta$-blockers, $\mathrm{n}(\%)$ & $102(86)$ & $105(89)$ & 0.552 \\
\hline ACE inhibitor/ARB, $n(\%)$ & $102(86)$ & $107(91)$ & 0.307 \\
\hline Statins, n (\%) & $67(57)$ & $70(59)$ & 0.692 \\
\hline Aspirin, n (\%) & $22(19)$ & $8(7)$ & 0.006 \\
\hline Thienopyridine, n (\%) & $13(11)$ & $17(15)$ & 0.404 \\
\hline \multicolumn{4}{|l|}{ Procedural data } \\
\hline Single-chamber device, $\mathrm{n}(\%)$ & $32(27)$ & $38(32)$ & \multirow{3}{*}{0.623} \\
\hline Dual-chamber device, n (\%) & $63(53)$ & $56(48)$ & \\
\hline Cardiac resynchronization device, $\mathrm{n}(\%)$ & $23(20)$ & $24(20)$ & \\
\hline PM, n (\%) & $79(67)$ & $76(64)$ & \multirow{2}{*}{0.681} \\
\hline ICD, n (\%) & $39(33)$ & $42(36)$ & \\
\hline De novo implantation, $\mathrm{n}(\%)$ & $89(75)$ & $94(80)$ & \multirow{3}{*}{0.390} \\
\hline Generator change, $\mathrm{n}(\%)$ & $13(11)$ & $12(10)$ & \\
\hline System upgrade, $\mathrm{n}(\%)$ & $16(14)$ & $12(10)$ & \\
\hline Procedure time, $(\min \pm S D)$ & $55 \pm 29$ & $59 \pm 39$ & 0.388 \\
\hline Subpectoral implantation, $\mathrm{n}(\%)$ & $3(3)$ & $1(1)$ & 0.313 \\
\hline
\end{tabular}

$\mathrm{ACE}$, angiotensin converting enzyme; ARB, angiotensin receptor blocker; CRD, cardiac rhythm device; ICD, implantable cardioverter-defibrillator; IQR, interquartile range; PM, pacemaker; SD, standard deviation.

\section{Methods}

\section{Patients}

For the purpose of this prospective case-control study, 118 consecutive patients who were periprocedurally treated with dabigatran between January 2011 and May 2013 were matched with respect to sex, age, procedural characteristics (ie, device and procedure type) and comorbidities (individual components of the $\mathrm{CHA}_{2} \mathrm{DS}_{2}-\mathrm{VASc}$ score) with 118 of 689 patients treated with uninterrupted warfarin during the same time period. The study population comprised 146 patients undergoing PM-related procedures, 62 patients undergoing ICD-related procedures (including 25 CRT procedures) and 28 patients undergoing system upgrade. Table 1 shows the detailed baseline characteristics and procedural data of both study groups. Because of dabigatranspecific contraindications, patients with severely reduced creatinine clearance (glomerular filtration rate $[\mathrm{GFR}]<30 \mathrm{ml} / \mathrm{min}$ ) and the elderly ( $>80$ years old) were not included in the study.

All patients provided written informed consent for device intervention and data collection and analysis.

\section{Periprocedural Anticoagulation Management}

In the dabigatran group, anticoagulation was administered for the first time post-procedurally in 33 patients $(28 \%)$ after a median of $12 \mathrm{~h}$ (interquartile range [IQR] 12-24h). These patients, the dabigatran-naïve group, were not receiving any anticoagulation nor were they treated with aspirin prior to admission. In the remaining 85 dabigatran-experienced patients (72\%), anticoagulation was discontinued $12 \mathrm{~h}$ before the procedure and re-administered after a median of $24 \mathrm{~h}$ (IQR $0-48 \mathrm{~h}$ ) post-procedurally. Patients were treated with $150 \mathrm{mg}(\mathrm{n}=48,41 \%)$ or
$110 \mathrm{mg}(\mathrm{n}=70,59 \%)$ dabigatran twice-daily, according to creatinine clearance $(150 \mathrm{mg}$ b.d. if GFR $>50 \mathrm{ml} / \mathrm{min} ; 110 \mathrm{mg}$ b.d. if GFR $<50 \mathrm{ml} / \mathrm{min}$ and $>30 \mathrm{ml} / \mathrm{min}$ ).

In the warfarin group, the anticoagulation intensity was targeted to an international normalized ratio (INR) between 2 and 3 and the median INR during the procedure was 2.1 (IQR 1.5-2.4). Most of the patients (56\%) were in the target INR range; however, 48 patients $(41 \%)$ had an unintentional subtherapeutic INR $<2$ and 4 patients $(3 \%)$ were overtreated (INR $>3$ ). Bridging with heparin was not performed in either group.

\section{Implantation Procedure}

Patients undergoing de novo implantation, generator change or system upgrade of PM, ICD or cardiac resynchronization therapy device were included. Most procedures were performed with standard techniques for subcutaneous pectoral pocket formation. In 4 cases (2\%), subpectoral pocket preparation was necessary. In all cases, the subclavian vein was used for lead insertion. The ICD leads were generally positioned at the right ventricular apex, and PM leads were positioned on the interventricular septum. According to our in-hospital recommendations, every patient without suspected intracardiac thrombi (excluded by transesophageal echocardiography or under well-documented anticoagulation) underwent defibrillation threshold testing at the end of the procedure. The scheduled time of first post-interventional dabigatran administration was left to the discretion of the implanting physician. All patients provided written informed consent for device intervention.

\section{Follow-up}

Routine follow-up examinations were performed on the first 
Table 2. Outcomes of Patients Treated With Dabigatran or Uninterrupted Warfarin After CRD Implantation

Dabigatran

( $n=118)$

Warfarin

Bleeding, $\mathrm{n}(\%)$

$3(3)$

$(n=118)$

$P$ value

Surgical revision, $\mathrm{n}(\%)$

$0(0)$

$9(8)$

0.075

Hemoglobin change, $(\mathrm{mmol} / \mathrm{L} \pm \mathrm{SD})$

Hemoglobin change $>10 \%, \mathrm{n}(\%)$

$-0.5 \pm 0.4$

2 (1)

0.156

Thromboembolic event, $n$ (\%)

$6(5)$

$-0.9 \pm 0.7$

0.023

1 (1)

$12(10)$

0.092

Mean time to discharge, (days $\pm \mathrm{SD}$ )

$2.5 \pm 2.3$

$3.8 \pm 4.1$

0.316

Abbreviations as in Table 1.

\begin{tabular}{|c|c|c|c|c|c|c|c|c|}
\hline Sex & $\begin{array}{c}\text { Age } \\
\text { (years) }\end{array}$ & $\begin{array}{l}\mathrm{CHA}_{2} \mathrm{DS}_{2-} \\
\text { VASc score }\end{array}$ & Procedure & $\begin{array}{l}\text { Preprocedural } \\
\text { anticoagulation }\end{array}$ & $\begin{array}{l}\text { Postprocedural } \\
\text { interruption of } \\
\text { anticoagulation } \\
\text { (h) }\end{array}$ & Complication & Revision & $\begin{array}{c}\text { Aspirin } \\
\text { and/or } \\
\text { thiopiridine }\end{array}$ \\
\hline \multicolumn{9}{|c|}{ Dabigatran $(n=4)$} \\
\hline M & 73 & 4 & $\begin{array}{c}\text { De novo } \\
\text { implantation of } \\
\text { single-chamber } \\
\text { PM }\end{array}$ & $\begin{array}{l}\text { Dabigatran } \\
\text { interrupted } 12 \mathrm{~h} \\
\text { prior procedure }\end{array}$ & No & $\begin{array}{c}\text { Pocket } \\
\text { hematoma }\end{array}$ & No & Yes \\
\hline M & 76 & 5 & $\begin{array}{l}\text { De novo } \\
\text { implantation of } \\
\text { dual-chamber } \\
\text { PM }\end{array}$ & $\begin{array}{l}\text { Warfarin with } \\
\text { labile INR of } 1.3\end{array}$ & 12 & $\begin{array}{c}\text { Pocket } \\
\text { hematoma }\end{array}$ & No & No \\
\hline M & 67 & 5 & $\begin{array}{l}\text { Subpectoral } \\
\text { de novo } \\
\text { implantation of } \\
\text { a CRT-D }\end{array}$ & Aspirin & 24 & $\begin{array}{c}\text { Pocket } \\
\text { hematoma }\end{array}$ & No & Yes \\
\hline M & 71 & 4 & $\begin{array}{l}\text { De novo } \\
\text { implantation of } \\
\text { a CRT-D }\end{array}$ & Aspirin & 12 & TIA & No & Yes \\
\hline \multicolumn{9}{|c|}{ Warfarin $(n=9)$} \\
\hline M & 83 & 4 & $\begin{array}{l}\text { System upgrade } \\
\text { to CRT-D }\end{array}$ & $\begin{array}{l}\text { Warfarin } \\
\text { (INR 2.28) }\end{array}$ & No & $\begin{array}{c}\text { Pocket } \\
\text { hematoma }\end{array}$ & Yes & No \\
\hline M & 63 & 4 & $\begin{array}{c}\text { Generator } \\
\text { change of } \\
\text { single-chamber } \\
\text { ICD }\end{array}$ & $\begin{array}{l}\text { Warfarin } \\
\text { (INR 1.55) }\end{array}$ & No & $\begin{array}{c}\text { Pocket } \\
\text { hematoma }\end{array}$ & No & No \\
\hline M & 80 & 5 & $\begin{array}{l}\text { System upgrade } \\
\text { to CRT-D }\end{array}$ & $\begin{array}{l}\text { Warfarin } \\
\text { (INR 2.13) }\end{array}$ & No & $\begin{array}{c}\text { Pocket } \\
\text { hematoma }\end{array}$ & No & Yes \\
\hline $\mathrm{F}$ & 70 & 4 & $\begin{array}{l}\text { De novo } \\
\text { implantation of } \\
\text { dual-chamber } \\
\text { PM }\end{array}$ & $\begin{array}{l}\text { Warfarin } \\
\text { (INR 1.84) }\end{array}$ & No & $\begin{array}{c}\text { Pocket } \\
\text { hematoma }\end{array}$ & No & No \\
\hline $\mathrm{F}$ & 81 & 5 & $\begin{array}{c}\text { De novo } \\
\text { implantation of } \\
\text { single-chamber } \\
\text { PM }\end{array}$ & $\begin{array}{l}\text { Warfarin } \\
\text { (INR 1.52) }\end{array}$ & No & $\begin{array}{c}\text { Pocket } \\
\text { hematoma }\end{array}$ & No & Yes \\
\hline M & 73 & 5 & $\begin{array}{l}\text { System upgrade } \\
\text { to CRT-P }\end{array}$ & $\begin{array}{l}\text { Warfarin } \\
\text { (INR 1.34) }\end{array}$ & No & $\begin{array}{c}\text { Pocket } \\
\text { hematoma }\end{array}$ & No & Yes \\
\hline M & 82 & 5 & $\begin{array}{l}\text { De novo } \\
\text { implantation of } \\
\text { CRT-D }\end{array}$ & $\begin{array}{l}\text { Warfarin } \\
\text { (INR 2.13) }\end{array}$ & No & $\begin{array}{c}\text { Pocket } \\
\text { hematoma }\end{array}$ & No & Yes \\
\hline$M$ & 69 & 6 & $\begin{array}{l}\text { System upgrade } \\
\text { to CRT-D }\end{array}$ & $\begin{array}{l}\text { Warfarin } \\
\text { (INR 1.35) }\end{array}$ & No & $\begin{array}{c}\text { Pocket } \\
\text { hematoma }\end{array}$ & No & No \\
\hline $\mathrm{F}$ & 81 & 3 & $\begin{array}{c}\text { De novo } \\
\text { implantation of } \\
\text { single-chamber } \\
\text { PM }\end{array}$ & $\begin{array}{l}\text { Warfarin } \\
\text { (INR 3.44) }\end{array}$ & No & $\begin{array}{c}\text { Pocket } \\
\text { hematoma }\end{array}$ & Yes & No \\
\hline
\end{tabular}

CRT-D, cardiac resynchronization therapy defibrillator; F, female; INR, international normalization ratio; M, male; TIA, transient ischemic attack. Other abbreviations as in Table 1. 


\begin{tabular}{|c|c|c|c|c|}
\hline & $\begin{array}{l}\text { Dabigatran-naïve } \\
\qquad(n=33)\end{array}$ & $\begin{array}{c}\text { Interrupted } \\
\text { dabigatran }(n=118)\end{array}$ & $\begin{array}{l}\text { Uninterrupted } \\
\text { Warfarin }(n=118)\end{array}$ & $P$ value \\
\hline \multicolumn{5}{|l|}{ Clinical characteristics } \\
\hline Age, (years $\pm S D$ ) & $71 \pm 11$ & $73 \pm 11$ & $74 \pm 10$ & 0.585 \\
\hline Male, $\mathrm{n}(\%)$ & $24(73)$ & $52(61)$ & $74(64)$ & 0.880 \\
\hline Diabetes mellitus, $\mathrm{n}(\%)$ & $8(24)$ & $23(27)$ & $40(34)$ & 0.275 \\
\hline Coronary artery disease, $\mathrm{n}(\%)$ & $7(21)$ & $28(33)$ & $38(32)$ & 0.975 \\
\hline Hypertension, n (\%) & $32(97)$ & $78(92)$ & $108(92)$ & 0.897 \\
\hline Median $\mathrm{CHA}_{2} \mathrm{DS}_{2}$-VASc score, (IQR) & $4(3-5)$ & $4(3-5)$ & $4(3-5)$ & 0.333 \\
\hline$\beta$-blockers, $\mathrm{n}(\%)$ & $28(85)$ & $74(87)$ & $105(89)$ & 0.657 \\
\hline ACE inhibitor/ARB, $n(\%)$ & $31(94)$ & $71(84)$ & $107(91)$ & 0.132 \\
\hline Statins, $n(\%)$ & $20(61)$ & $47(55)$ & $70(59)$ & 0.581 \\
\hline Aspirin, n (\%) & $5(15)$ & $17(20)$ & $8(7)$ & 0.005 \\
\hline Thienopyridine, n (\%) & $2(6)$ & $11(13)$ & $17(15)$ & 0.667 \\
\hline \multicolumn{5}{|l|}{ Procedural data } \\
\hline Single-chamber device, n (\%) & $8(24)$ & $24(28)$ & $38(32)$ & \multirow{3}{*}{0.627} \\
\hline Dual-chamber device, n (\%) & $20(61)$ & $43(51)$ & $56(48)$ & \\
\hline Cardiac resynchronization device, $n(\%)$ & $5(15)$ & $18(21)$ & $24(20)$ & \\
\hline $\mathrm{PM}, \mathrm{n}(\%)$ & $24(73)$ & $55(65)$ & $76(64)$ & \multirow{2}{*}{0.920} \\
\hline ICD, n (\%) & $9(27)$ & $30(35)$ & $42(36)$ & \\
\hline De novo implantation, $\mathrm{n}(\%)$ & $25(76)$ & $64(75)$ & $94(80)$ & \multirow{3}{*}{0.445} \\
\hline Generator change, $\mathrm{n}(\%)$ & $3(9)$ & $10(12)$ & $12(10)$ & \\
\hline System upgrade, $\mathrm{n}(\%)$ & $5(15)$ & $11(13)$ & $12(10)$ & \\
\hline Procedure time, $(\min \pm S D)$ & $51 \pm 29$ & $56 \pm 29$ & $59 \pm 39$ & 0.533 \\
\hline Subpectoral implantation, $\mathrm{n}(\%)$ & $1(3)$ & $2(3)$ & $1(1)$ & 0.392 \\
\hline
\end{tabular}

Abbreviations as in Table 1.

postoperative day, at discharge and after 1 month. During the follow-up examinations the implantation site was reassessed by 2 experienced physicians who focused on pocket hematomas and the necessity for surgical revisions. Pocket hematoma was reported if it caused prolongation of hospitalization, discontinuation of the anticoagulant or the necessity for transfusion of blood products. Surgical intervention was required if none of the conservative measures lead to sufficient reduction of the bleeding. Furthermore, in all patients (with exclusion of patients undergoing generator change) the existence of pericardial effusion was assessed by cardiac ultrasound.

Any cerebral thromboembolic events, including transient ischemic attacks, occurring within 30 days were reported.

Perioperative blood loss was defined as a decrease of the hemoglobin level in whole blood samples drawn before and $24 \mathrm{~h}$ after the procedure. Significant blood loss was defined as a drop in the hemoglobin level $\geq 10 \%$.

\section{Statistical Analysis}

Continuous variables are expressed as mean and standard deviation (SD). Categorical variables are reported as frequencies and percentage. Continuous variables were compared by Student's- $t$ test or ANOVA test, and categorical data by Chi-square test. For post-hoc analysis, a Bonferroni test was used. A 2-tailed P-value less than 0.05 was considered statistically significant. Analysis was performed with SPSS v 20.0 (SPSS Inc, Chicago, IL, USA).

\section{Results}

\section{Comparison of Patients Characteristics}

Patients in both groups were of similar age $(73 \pm 11$ vs. $74 \pm 10$ years, $\mathrm{P}=\mathrm{NS}$ ) and were mainly male (64\% vs. $64 \%, \mathrm{P}=\mathrm{NS})$. The mean procedural time was similar in both groups $(55 \pm 29 \mathrm{vs}$. $59 \pm 39 \mathrm{~min}, \mathrm{P}=\mathrm{NS})$. In 3 patients taking dabigatran (3\%) and in 1 patient $(1 \%)$ taking warfarin, subpectoral implantation was performed $(\mathrm{P}=\mathrm{NS})$. Most of the patients in both groups received dual-chamber or cardiac resynchronization devices (73\% vs. $68 \%$ ) as opposed to single-chamber systems (27\% vs. $32 \%$ ). In both groups, the most frequently performed procedures were de novo implantations ( $75 \%$ vs. $80 \%$ ), as compared with generator changes (11\% vs. $10 \%)$ and system upgrades (14\% vs. $10 \%)$. Patients in the dabigatran group were more frequently comedicated with aspirin $(\mathrm{P}=0.018)$. The median $\mathrm{CHA}_{2} \mathrm{DS}_{2-}$ VASc score was comparable between groups (4 [IQR 3-5] vs. 4 [IQR 3-5]) (P=NS).

\section{Complications}

Outcomes and detailed complication characteristics are summarized in Tables 2 and 3, respectively. In the warfarin group, there were $9(8 \%)$ pocket hematomas compared with $3(3 \%)$ in the dabigatran group $(\mathrm{P}=0.075)$. Two complications in the warfarin group needed surgical intervention as opposed to none in the dabigatran group $(\mathrm{P}=0.156)$. Neither the interval to first administration nor the dose of dabigatran was associated with the bleeding rates (Table 2). The perioperative blood loss expressed as a drop in hemoglobin was significantly greater in the warfarin group $(-0.9 \pm 0.7$ vs. $-0.5 \pm 0.4 \mathrm{mmol} / \mathrm{L}, \mathrm{P}=0.023)$. In 12 warfarin patients there was significant blood loss compared with 6 patients in the dabigatran group $(\mathrm{P}=0.092)$. However, no patient required a blood transfusion.

In 1 patient (male, 71 years old, undergoing cardiac resynchronization-ICD implantation, with $\mathrm{CHA}_{2} \mathrm{DS}_{2}-\mathrm{VASc}$ score of 4) treated preoperatively with aspirin and in whom $150 \mathrm{mg}$ 


\begin{tabular}{|c|c|c|c|c|}
\hline & $\begin{array}{l}\text { Dabigatran-naïve } \\
\qquad(n=33)\end{array}$ & $\begin{array}{c}\text { Interrupted } \\
\text { dabigatran }(n=118)\end{array}$ & $\begin{array}{c}\text { Uninterrupted } \\
\text { Warfarin }(n=118)\end{array}$ & $P$ value \\
\hline Bleeding, $n(\%)$ & $1(3)$ & 2 (3) & $9(8)$ & 0.086 \\
\hline Surgical revision, $\mathrm{n}(\%)$ & $0(0)$ & $0(0)$ & $2(2)$ & 0.184 \\
\hline Hemoglobin change, $(\mathrm{mmol} / \mathrm{L} \pm \mathrm{SD})$ & $-0.6 \pm 0.4$ & $-0.4 \pm 0.4$ & $-0.9 \pm 0.7$ & 0.048 \\
\hline Hemoglobin change $>10 \%, \mathrm{n}(\%)$ & $3(10)$ & $3(4)$ & $12(10)$ & 0.059 \\
\hline Thromboembolic event, $\mathrm{n}(\%)$ & $1(3)$ & $0(0)$ & $0(0)$ & 0.879 \\
\hline Mean time to discharge, $($ days $\pm S D)$ & $2.5 \pm 1.6$ & $2.5 \pm 2.6$ & $3.8 \pm 4.1$ & 0.009 \\
\hline
\end{tabular}

Abbreviations as in Table 1.

dabigatran was initiated $12 \mathrm{~h}$ after the procedure, a transient ischemic attack without any lasting neurological deficits occurred. There were no thromboembolic events in the warfarin group $(\mathrm{P}=\mathrm{NS})$.

Patients in the dabigatran group had a significantly shorter median time to discharge as compared with the warfarin group (2.5 \pm 2.3 vs. $3.8 \pm 4.1$ days, $\mathrm{P}=0.002$ ).

\section{Comparison of Dabigatran-Naïve, Interrupted Dabigatran and Uninterrupted Warfarin Groups}

There were no significant differences in terms of baseline and procedural characteristic among the patients in the dabigatrannaïve, interrupted dabigatran and uninterrupted warfarin group (Table 4). The bleeding complication rate was the highest in the uninterrupted warfarin group and similar in both the dabigatran-naïve and interrupted dabigatran group (8\% vs. $3 \%$ vs. $3 \%, \mathrm{P}=0.086)$.

The perioperative blood loss was similar in both dabigatran groups and significantly lower than in the warfarin group $(-0.6 \pm 0.4$ vs. $-0.4 \pm 0.4$ vs. $-0.9 \pm 0.7 \mathrm{mmol} / \mathrm{L}, \mathrm{P}=0.048$ between all groups; $\mathrm{P}=\mathrm{NS}$ between dabigatran-naïve and warfarin groups; $\mathrm{P}=0.043$ between interrupted dabigatran and warfarin groups; $\mathrm{P}=\mathrm{NS}$ between dabigatran-naïve and interrupted dabigatran groups). Although not reaching statistical significance, blood loss $>10 \%$ was less frequently observed in the interrupted dabigatran group than in either the dabigatran-naïve or warfarin group ( $4 \%$ vs. $10 \%$ vs. $10 \%, \mathrm{P}=0.059$ ).

Furthermore, a shorter time to discharge was observed for both dabigatran groups ( $2.5 \pm 1.6$ vs. $2.5 \pm 2.6$ vs. $3.8 \pm 4.1$ days, $\mathrm{P}=0.009$ between all groups; $\mathrm{P}=\mathrm{NS}$ between dabigatran-naïve and warfarin groups; $\mathrm{P}=0.018$ interrupted dabigatran and warfarin groups; $\mathrm{P}=\mathrm{NS}$ between dabigatran-naïve and interrupted dabigatran groups).

The duration of dabigatran interruption had no influence on the frequency of bleeding complications $(27 \pm 22 \mathrm{~h}$ in non-bleeding group vs. $12 \pm 12 \mathrm{~h}$ in bleeding group, $\mathrm{P}=\mathrm{NS}$ ).

Table $\mathbf{5}$ is a comparison of the outcome data for the 3 groups.

\section{Discussion}

To the best of our knowledge, this is the first case-control study comparing complications in patients undergoing CRD implantation under dabigatran or uninterrupted warfarin. Although not reaching statistical significance, we observed almost 3-fold more bleeding complications in the warfarin group and $20 \%$ of those had to be treated surgically whereas all complications in the dabigatran group were treated conservatively. Therefore, our results are in accordance with the reports from the RE-LY study population showing that if dabigatran is discontinued preprocedurally the incidence of bleeding complications may be lower than during uninterrupted warfarin therapy. ${ }^{7,8}$ Considering our data and the comparable bleeding rates in the very recently published BRUISE CONTROL study under warfarin, ${ }^{6}$ dabigatran may even be associated with superior safety but optimal peri-interventional management must still be elaborated.

The routine clinical use of NOACs, such as the direct thrombin inhibitor dabigatran, has the potential to simplify peri-procedural anticoagulation management because of the relatively short half-life time, rapid onset of action, predictable pharmacokinetic properties and few drug-drug interactions. In our study, we found shortened hospitalization and reduced blood loss, emphasizing the presumed advantages of modern anticoagulation agents. Furthermore, of note is that dabigatran use was safe despite significantly more frequent comedication with aspirin, which can potentially increase complication rates. ${ }^{1}$

It might be expected that the difference in hospitalization was driven by prolonged time to discharge for 9 patients with bleeding under warfarin and 2 necessitating revision (vs. 3 cases of bleeding and no cases of revisions in the dabigatran group). However, even after exclusion of these cases, hospitalization was still significantly shorter in the dabigatran group (2.3 \pm 1.7 vs. $3.5 \pm 3.8, \mathrm{P}=0.003$ ). In that context, we believe that the prolonged hospitalization might be related to longer recovery secondary to subclinical hematomas, higher demand for painkillers, need for hemoglobin control, or correction of INR back to the therapeutic level.

Although no association between higher doses of dabigatran and bleeding complications was observed in our study, it can not be excluded that the application of higher dose in countries where the $110 \mathrm{mg}$ dose is not approved may influence bleeding rates.

On the other hand, because the novel agents with fast elimination do not provide an overlapping thromboembolic prophylaxis after discontinuation, their efficacy regarding thromboembolic events must be further examined and optimal peri-interventional management must be established. Although our results reflect early observations with a new drug and therefore include different approaches concerning continuation or re-initiation of anticoagulation ranging from uninterrupted therapy up to $72 \mathrm{~h}$ of discontinuation, it seems that this aspect has no major influence on periprocedural complications. In that context, it is advisable to reduce the time span in which patients remain at risk for thromboembolic events to the minimum.

As reported recently, dabigatran has been rapidly adopted into ambulatory practice for the treatment of $\mathrm{AF}$ and a further rise is to be expected. ${ }^{9}$ Therefore, the periprocedural management of patients who are receiving modern anticoagulation therapy is a rapidly growing and complex clinical problem that requires further careful evaluation. 


\section{Study Limitations}

Despite the novelty of our findings and so far the largest sample size, our study is still limited by heterogeneous anticoagulation management, diverse procedures and non-randomized study design. Further, larger and randomized studies are needed to clarify the role of new anticoagulants and define the optimal anticoagulation strategy in patients undergoing CRD implantation. Our results can not be extrapolated to uninterrupted treatment with dabigatran as therapy was conducted in accordance with current guidelines. ${ }^{10}$ However, this issue will be resolved by the ongoing BRUISE CONTROL-2 trial (NCT01675076).

Regrettably, but as is usual in the real-world setting, there was inadequate anticoagulation use with relatively low INR in the warfarin group and relatively high incidence of aspirin comedication in the dabigatran group.

Because dabigatran is contraindicated in elderly patients and/or with severely impaired kidney function this population was not included in our study.

\section{Conclusions}

The incidence and severity of bleeding complications may be lower in patients treated with periprocedurally discontinued dabigatran therapy when compared with uninterrupted warfarin therapy. Further evaluation of peri-interventional complications and establishment of an optimal anticoagulation management protocol is needed.

\section{Disclosures}

None.

\section{References}

1. Bernard ML, Shotwell M, Nietert PJ, Gold MR. Meta-analysis of bleeding complications associated with cardiac rhythm device implantation. Circ Arrhythm Electrophysiol 2012; 5: 468-474.

2. Yokoshiki H, Mitsuyama H, Watanabe M, Mizukami K, Matsui Y, Tsutsui H. Anticoagulation management in the perioperative phase of implantable cardioverter defibrillator implantation. Circ J 2013; 77: 2003-2008.

3. Ohlow MA, Lauer B, Brunelli M, Geller JC. Incidence and predictors of pericardial effusion after permanent heart rhythm device implantation: Prospective evaluation of 968 consecutive patients. Circ J 2013; 77: 975-981.

4. Özcan KS, Osmonov D, Yıldırım E, Altay S, Türkkan C, Ekmekçi A, et al. Hematoma complicating permanent pacemaker implantation: The role of periprocedural antiplatelet or anticoagulant therapy. J Cardiol 2013; 62: 127-130.

5. Tolosana JM, Berne P, Mont L, Heras M, Berruezo A, Monteagudo $\mathrm{J}$, et al. Preparation for pacemaker or implantable cardiac defibrillator implants in patients with high risk of thrombo-embolic events: Oral anticoagulation or bridging with intravenous heparin? A prospective randomized trial. Eur Heart J 2009; 30: 1880-1884.

6. Birnie DH, Healey JS, Wells GA, Verma A, Tang AS, Krahn AD, et al. Pacemaker or defibrillator surgery without interruption of anticoagulation. N Engl J Med 2013; 368: 2084-2093.

7. Rowley CP, Bernard ML, Brabham WW, Netzler PC, Sidney DS, Cuoco F, et al. Safety of continuous anticoagulation with dabigatran during implantation of cardiac rhythm devices. Am J Cardiol 2013; 111: $1165-1168$.

8. Healey JS, Eikelboom J, Douketis J, Wallentin L, Oldgren J, Yang $\mathrm{S}$, et al. Periprocedural bleeding and thromboembolic events with dabigatran compared with warfarin: Results from the Randomized Evaluation of Long-Term Anticoagulation Therapy (RE-LY) randomized trial. Circulation 2012; 126: 343-348.

9. Kirley K, Qato DM, Kornfield R, Stafford RS, Alexander GC. National trends in oral anticoagulant use in the United States, 2007 to 2011. Circ Cardiovasc Qual Outcomes 2012; 5: 615-621.

10. Heidbuchel H, Verhamme P, Alings M, Antz M, Hacke W, Oldgren $\mathrm{J}$, et al. Practical Guide on the use of new oral anticoagulants in patients with non-valvular atrial fibrillation. Europace 2013; 15: 625651. 